\title{
POETRY
}

\section{A man presents with radiating chest pain}

This is what I see.

A middle-aged man whose eyes

reflect three dots of light from the ceiling,

like a magazine portrait of an important person.

He's been selling shoes for 37 years.

I guess I could believe him if he said

he was the type of salesman

to save boys from themselves,

from burgundy shoes and brown suits.

He knows that chest pain could be anything.

From the way he folds his limbs neatly,

I think he will be sorry if it is just acid.

Like someone whose $10 / 10$ pain is watching

someone else's most embarrassing moment,

whose $1 / 10$ is the weight of a

sibling's head during Jeopardy!

So when he says he is $8 / 10$, I think of it

between the pain of watching childbirth

and stubbing a toe on an exlover's suitcase.

It is story-time. I practise listening.

I give his setting biblical powers.

I turn his ordinary snowstorm into God's dandruff.

When he says he pulled over from pain

at a "Timmy's and Wendy's," - what is that?

I think of the house of a separated

couple, without the courage to leave.

Timmy has large hands and is losing his sense of smell.

Wendy was happiest as an assistant cheerleader.

My patient pulled over at their curb.

They were neighbourly enough to call 911.

I guess they saw more in his pained

breathing than he thought he showed.

Now he is at 30 breaths per minute,

and his blood pressure is $180 / 90$.

When the attending physician comes, I will say,

"Sir, I think he's having a heart attack."

The attending physician might repeat my questions,

look at the lab results and say,

"Sir, you're having a heart attack."

The cardiology resident will be paged.

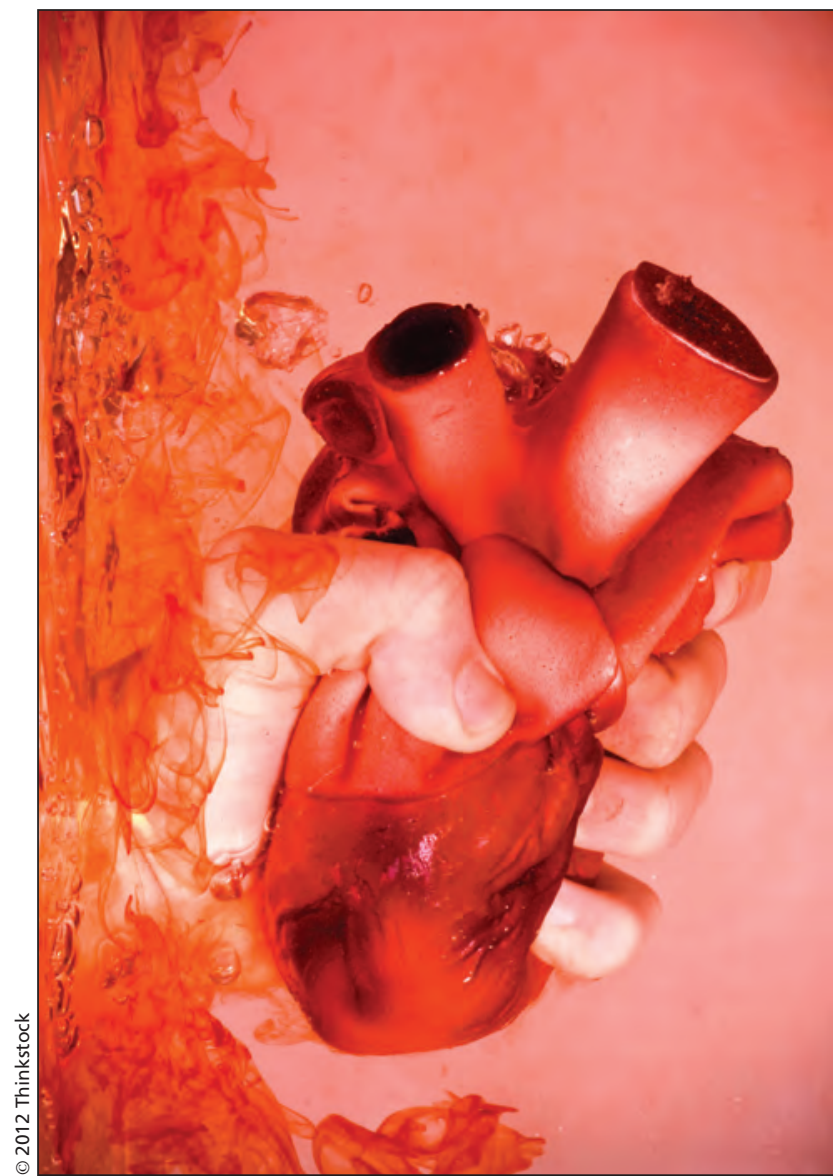

He will say, "Sir, you're having a heart attack." The attending cardiologist will come down and, with more authority,

"Sir, you're having a heart attack."

Sir, you're having a heart attack.

I'm sorry, I guess.

Jinghao Mary Yang

Third-year medical student

Faculty of Medicine

University of Toronto

Toronto, Ont.

CMAJ 2012. DOI:10.1503/cmaj.121031 